\title{
Sliding mode control design for autonomous surface vehicle motion under the influence of environmental factor
}

\author{
Hendro Nurhadi ${ }^{1}$, Erna Apriliani ${ }^{2}$, Teguh Herlambang ${ }^{3}$, Dieky Adzkiya ${ }^{4}$ \\ ${ }^{1}$ Department of Mechanical Engineering, Faculty of Industrial Technology, \\ Institut Teknologi Sepuluh Nopember (ITS), Indonesia \\ ${ }^{2,4}$ Department of Mathematics, Faculty of Science and Data Analytics, \\ Institut Teknologi Sepuluh Nopember (ITS), Indonesia \\ ${ }^{3}$ Study Program of Information Systems, Faculty of Engineering, \\ Universitas Nahdlatul Ulama Surabaya (UNUSA), Indonesia \\ ${ }^{1,4}$ Center of Excellence Mechatronics and Industrial Automation Research Center, \\ Institut Teknologi Sepuluh Nopember (ITS), Indonesia
}

\begin{tabular}{l}
\hline \hline Article Info \\
\hline Article history: \\
Received Oct 14, 2019 \\
Revised Feb 27, 2020 \\
Accepted Mar 21, 2020 \\
\hline
\end{tabular}

Keywords:

Autonomous surface vehicle Control systems

Environmental factors

Nonlinear model

Sliding mode control

\begin{abstract}
Autonomous Surface Vehicle (ASV) is a vehicle that is operated in the water surface without any person in the vehicle. Since there is no person in the ASV, a motion controller is essentially needed. The control system is used to make sure that the water vehicle is moving at the desired speed. In this paper, we use a Touristant ASV with the following specifications: the length is 4 meters, the diameter is 1.625 meters, and the height is 1.027 meters. The main contribution of this paper is applying the Sliding Mode Control system to the Touristant ASV model under the influence of environmental factors. The environmental factors considered in this work are wind speed and wave height. The Touristant ASV model is nonlinear and uses three degree of freedom (DOF), namely surge, sway and yaw. The simulation results show that the performance of the closed-loop system by using the SMC method depends on the environmental factors. If environmental factors are higher, then the resulting error is also higher. The average error difference between those resulted from the simulation without environmental factors and those with the influence of environmental factors is $0.05 \%$ for surge, sway and yaw motions.
\end{abstract}

Copyright () 2020 Insitute of Advanced Engineeering and Science. All rights reserved.

\section{Corresponding Author:}

Teguh Herlambang,

Study Program of Information Systems, Faculty of Engineering,

Universitas Nahdlatul Ulama Surabaya (UNUSA),

Jl. Raya Jemursari 51-57, Surabaya, Indonesia.

Email: teguh@unusa.ac.id

\section{INTRODUCTION}

Indonesia is one of the countries in the world where approximately $70 \%$ of the area is sea $[1,2]$. Such condition makes Indonesia a suitable place to develop marine and coastal tourism. There are many marine and coastal tourisms in Indonesia. One of them is Kenjeran Beach, that is located in Surabaya. At Kenjeran Beach, tourists can enjoy the view by riding a simple boat that is operated by humans. Boat operation by humans may cause accidents due to negligence, lack of professionalism and some other reasons. To reduce the number of accidents and along with technological developments, a vehicle called Autonomous Surface Vehicle (ASV) can be utilized as a support for marine and coastal tourisms.

An Autonomous Surface Vehicle (ASV) is an unmanned on-water vehicle that is able to navigate automatically in water area $[3,4]$. There are many works on ASV in the literature. We will mention some of 
them here. ASV have been applied in many aspects, such as water quality monitoring [5], risk assessment [6] and network centric operations [7]. There are also some papers on modeling, control and estimation of ASV and autonomous unmanned vehicle [8], for example tracking control using neural network approach [9], adaptive dynamic surface control [10], path following [11], obstacle detection and avoidance [12, 13], target tracking [14], stability analysis [1], estimation using square root ensemble Kalman filter [2, 15], Proportional Integral Derivative (PID) control design [16], control design using Sliding Mode Control (SMC) [17-19], sliding PID control design [20, 21], using Particle Swarm Optimization (PSO) and Ant Colony Optimization (ACO) for Optimizing PID Parameters on Autonomous Underwater Vehicle (AUV) [22], estimation using ensemble Kalman filter [23, 24] and estimation using fuzzy Kalman filter [25].

In this paper, we discuss control design for ASV by using SMC. There are many advantages of using SMC, for example it is robust and it can be applied to nonlinear systems. The ASV model discussed in this paper has three degrees of freedom, namely surge, sway and yaw. The disturbances considered are wind speed and wave height. This paper is structured as follows. The modeling of ASV is discussed in Section 2. Then the general control design using SMC is described in Section 3. The control design of ASV by using SMC is explained in Section 4. The simulation results are discussed in Section 5. Finally, the conclusions are written in Section 6.

\section{AUTONOMOUS SURFACE VEHICLE}

Autonomous Surface Vehicle (ASV) is equipped with Global Positioning System (GPS), sensors, gas, pH sensors, bluetooth, and telemetry. When the location has been determined, the vehicle will move automatically in real-time. Besides research water vehicle, ASV can also be used for other purposes, such as survey vehicle, inspection of river conditions, seismic surveys, rescue operations etc. The profile and specification of Touristant ASV are listed in Figure 1 and Table 1.

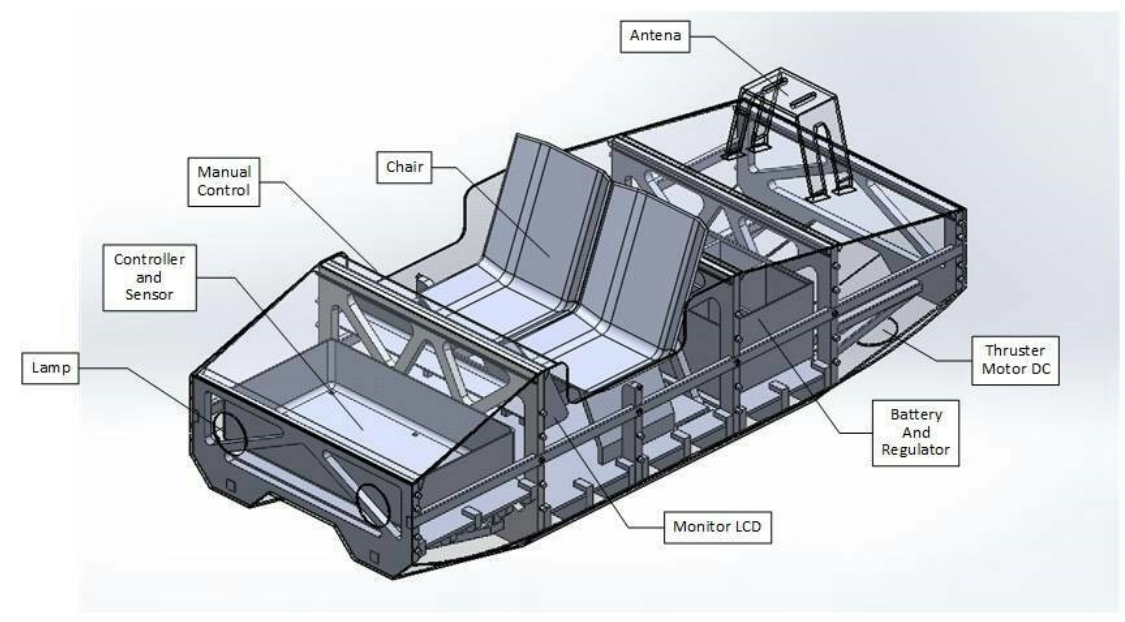

Figure 1. Profile of Touristant ASV

Table 1. Specification of Touristant ASV

\begin{tabular}{cccc}
\hline Length & Bean & Depth & DWL \\
\hline $4.12 \mathrm{~m}$ & $1.625 \mathrm{~m}$ & $1.027 \mathrm{~m}$ & $0.3 \mathrm{~m}$ \\
\hline
\end{tabular}

In general, the water-vehicle motions are divided into two types, namely translational and rotational motions. Translational motion consists of surge, sway and heave, whereas rotational motion comprises of roll, pitch, and yaw [18]. In this paper, we use the equation of water-vehicle motions with 3 degrees of freedom (DOF), namely surge, sway and, yaw. The mathematical model for surge, sway and yaw motions is given by 


$$
\begin{aligned}
& \left(m-X_{\dot{u}}\right) \dot{u}=X_{|u| u}|u| u+(1-h) X_{\text {prop }}+\left(m+X_{v r}\right) v r+\left(m x_{G}+X_{r r}\right) r^{2}+X_{\delta \delta} \delta^{2}+X_{\text {ext }}, \\
& \left(m-Y_{\dot{v}}\right) \dot{v}+\left(m x_{G}-Y_{\dot{r}}\right) \dot{r}=-\left(m-Y_{u r}\right) u r+Y_{u v} u v+Y_{|v| v}|v| v+Y_{|v| r}|v| r+Y_{\delta} \delta+Y_{e x t}, \\
& \left(m x_{G}-N_{\dot{v}}\right) \dot{v}+\left(I_{z}-N_{\dot{r}}\right) \dot{r}=-\left(m x_{G}-N_{u r}\right) u r+N_{u v} u v+N_{|v| v}|v| v+N_{|v| r}|v| r+N_{\delta} \delta+N_{e x t},
\end{aligned}
$$

From (1)-(3), $X_{\text {ext }}, Y_{\text {ext }}$ and $N_{\text {ext }}$ represent an interference from outside of the surge, sway and yaw motions. In this study, the external interference or environmental factors considered are the force on wind speed, force on wave height, moment of wind speed and force on wave height. It follows that the equations are as follows

$$
\begin{aligned}
& X_{\text {ext }}=X_{\text {wind }}+X_{\text {waves }}, \\
& Y_{\text {ext }}=Y_{\text {wind }}+Y_{\text {waves }}, \\
& N_{\text {ext }}=N_{\text {wind }}+N_{\text {waves }},
\end{aligned}
$$

From the description of $X_{e x t}, Y_{e x t}$ and $N_{e x t}$, the following nonlinear equations are obtained:

$$
\begin{aligned}
& \left(m-X_{\dot{u}}\right) \dot{u}=X_{|u| u}|u| u+(1-h) X_{\text {prop }}+\left(m+X_{v r}\right) v r+\left(m x_{G}+X_{r r}\right) r^{2}+X_{\delta \delta} \delta^{2} \\
& \quad+X_{\text {wind }}+X_{\text {waves }}, \\
& \left(m-Y_{\dot{v}}\right) \dot{v}+\left(m x_{G}-Y_{\dot{r}}\right) \dot{r}=-\left(m-Y_{u r}\right) u r+Y_{u v} u v+Y_{|v| v}|v| v+Y_{|v| r}|v| r+Y_{\delta} \delta \\
& \quad+Y_{\text {wind }}+Y_{\text {waves }}, \\
& \quad\left(m x_{G}-N_{\dot{v}}\right) \dot{v}+\left(I_{z}-N_{\dot{r}}\right) \dot{r}=-\left(m x_{G}-N_{u r}\right) u r+N_{u v} u v+N_{|v| v}|v| v+N_{|v| r}|v| r+N_{\delta} \delta \\
& \quad+N_{\text {wind }}+N_{\text {waves }},
\end{aligned}
$$

In the following, we define three variables $U_{\text {surge }}, V_{\text {sway }}$ and $N_{\text {yaw }}$ which will be used later

$$
\begin{aligned}
& U_{\text {surge }}=X_{|u| u}|u| u+\left(m+X_{v r}\right) v r+\left(m x_{G}+X_{r r}\right) r^{2}+X_{\delta \delta} \delta^{2}+X_{\text {wind }}+X_{\text {waves }}, \\
& V_{\text {sway }}=-\left(m-Y_{u r}\right) u r+Y_{u v} u v+Y_{|v| v}|v| v+Y_{|v| r}|v| r+Y_{\text {wind }}+Y_{\text {waves }}, \\
& N_{\text {yaw }}=-\left(m x_{G}-N_{u r}\right) u r+N_{u v} u v+N_{|v| v}|v| v+N_{|v| r}|v| r+N_{\text {wind }}+N_{\text {waves }},
\end{aligned}
$$

Equations (7)-(9) are quite long and complicated. In order to simplify those three equations, we use the newly introduced $U_{\text {surge }}, V_{\text {sway }}$ and $N_{\text {yaw }}$, as follows

$$
\begin{aligned}
& \left(m-X_{\dot{u}}\right) \dot{u}=(1-h) X_{\text {prop }}+U_{\text {surge }}, \\
& \left(m-Y_{\dot{v}}\right) \dot{v}+\left(m x_{G}-Y_{\dot{r}}\right) \dot{r}=Y_{\delta} \delta+V_{\text {sway }}, \\
& \left(m x_{G}-N_{\dot{v}}\right) \dot{v}+\left(I_{z}-N_{\dot{r}}\right) \dot{r}=N_{\delta} \delta+N_{\text {yaw }},
\end{aligned}
$$

The mathematical model of Touristant ASV is described in (13)-(15). In order to apply the sliding mode control design, it is better if the mathematical model is written in a state-space form. The state-space form of the mathematical model is as follows

$$
\begin{aligned}
& \dot{u}=T_{1}\left((1-h) X_{\text {prop }}+U_{\text {surge }}\right), \\
& \dot{v}=T_{2}\left(Y_{\delta} \delta_{1}+V_{\text {sway }}\right)+T_{3}\left(N_{\delta} \delta_{1}+N_{\text {yaw }}\right), \\
& \dot{r}=T_{4}\left(Y_{\delta} \delta_{2}+V_{\text {sway }}\right)+T_{5}\left(N_{\delta} \delta_{2}+N_{\text {yaw }}\right),
\end{aligned}
$$

where $T_{1}, T_{2}, \ldots, T_{5}$ are constants, $\delta_{1}$ is the variable associated with sway and $\delta_{2}$ is the variable associated with yaw. The state variables are $u, v, r$ and the input variables are $X_{\text {prop }}, \delta_{1}$ and $\delta_{2}$.

\section{SLIDING MODE CONTROL}

In order to apply the Sliding Mode Control (SMC), we follow the flowchart shown in Figure 2. The detailed stages of SMC implementation can be summarized as follows [17, 25]:

1. Determine switching function $S(x, t)$ from the tracking error At the stage of determining the switching function, each ASV motion state is associated with a switching function using the following equations:

$$
S(x, t)=\left(\frac{d}{d t}+\lambda\right)^{n-1} \tilde{x}(t),
$$

where tracking error can be expressed as $\tilde{x}(t)=x(t)-x_{d}(t)$ and $x_{d}$ is the desired state. 
2. Determine the sliding surface

The next step is to determine the sliding surface, namely $S(x, t)=0$ from the switching function obtained.

3. Determine the controller estimation value $\hat{a}$

The step to determine the controller estimation value $\hat{a}$ can be obtained from the equation $\dot{S}=0$.

4. Use control law $a=\hat{a}-K \operatorname{sgn}(S)$

The next step is applying the control law by using the equation:

$$
a=\hat{a}-K \operatorname{sgn}(S)
$$

To satisfy the sliding condition, the signum function is defined as follows:

$$
\operatorname{sgn}(x)= \begin{cases}-1, & \text { if } x<0 \\ 0, & \text { if } x=0 \\ 1, & \text { if } x>0\end{cases}
$$

5. Subtitute the value of $\hat{a}$

Subtitute the value $\hat{a}$ to control law so that new control input is obtained as the subtitute of the previous control input.

6. Determine the value of $K$

Determine the value $K$ from control law $a=\hat{a}-K \operatorname{sgn}(S)$ that has been obtained.

7. Saturation function

The last step is to change the signum function into a saturation function which aims is to minimize the chattering.



Figure 2. The flowchart of sliding mode control 


\section{SLIDING MODE CONTROL DESIGN FOR AUTONOMOUS SURFACE VEHICLE MODELS}

As mentioned in the previous section, the design of SMC for Nonlinear ASV model consists of three parts, namely for surge, sway and yaw motions.

\subsection{SMC design for surge motion}

In designing the control of surge motion, first of all notice that the tracking error of surge motion is $\tilde{u}=u-u_{d}$, where the desired surge $u_{d}$ is constant. Because the system has order 1 , the switching function is formed from (19) by defining $n=1$ as follows:

$$
S_{1}(u, t)=\tilde{u}=u-u_{d}
$$

Since $u_{d}$ is a constant function, $\dot{u}_{d}=0$. It follows that the derivative of $S_{1}(u, t)$ is

$$
\dot{S}_{1}(u, t)=\dot{u}-\dot{u}_{d}=\dot{u} .
$$

Then we substitute (16) to (20) to obtain the following equation:

$$
\dot{S}_{1}(u, t)=T_{1}\left((1-h) X_{\text {prop }}+U_{\text {surge }}\right) .
$$

In order to compute the estimated value of $X_{\text {prop }}$, denoted by $\hat{X}_{\text {prop }}, \dot{S}_{1}(u, t)$ is set to zero:

$$
0=T_{1}\left((1-h) \hat{X}_{\text {prop }}+U_{\text {surge }}\right)
$$

We obtain the following expression

$$
\hat{X}_{\text {prop }}=\frac{-U_{\text {surge }}}{1-h} .
$$

Based on the control law that meets the sliding condition, the relationship between $X_{\text {prop }}$ and $\hat{X}_{\text {prop }}$ shall be

$$
X_{\text {prop }}=\hat{X}_{\text {prop }}-K_{1} \operatorname{sgn}\left(S_{1}\right) \text {. }
$$

By substituting (23) into (24), we obtain

$$
X_{\text {prop }}=\frac{-U_{\text {surge }}}{1-h}-K_{1} \operatorname{sgn}\left(S_{1}\right) .
$$

Then we substitute (25) to (21), as follows

$$
\begin{aligned}
\dot{S}_{1}(u, t) & =T_{1}\left((1-h)\left(\frac{-U_{\text {surge }}}{1-h}-K_{1} \operatorname{sgn}\left(S_{1}\right)\right)+U_{\text {surge }}\right) \\
& =-T_{1}(1-h) K_{1} \operatorname{sgn}\left(S_{1}\right) .
\end{aligned}
$$

Then $K_{1}$ is chosen such that the sliding condition is fulfilled, that is

$$
S_{1} \dot{S}_{1} \leq-\eta\left|S_{1}\right|
$$

where $\eta$ is a tuning parameter. After some simple algebraic manipulations, we obtain

$$
K_{1} \geq \frac{\eta}{T_{1}(1-h) \operatorname{sgn}\left(S_{1}\right)} .
$$

From (27), the value of $K_{1}$ is

$$
K_{1}=\max \left|\frac{\eta}{T_{1}(1-h)}\right| .
$$

Then, a boundary layer is used to minimize chattering by changing the signum function (sgn) into saturation function as follows:

$$
X_{\text {prop }}=\hat{X}_{\text {prop }}-K_{1} \text { sat }\left(\frac{S_{1}}{\phi}\right)
$$


where $\phi$ is a tuning parameter. Finally the control input $X_{\text {prop }}$ is defined in the following equation

$$
X_{\text {prop }}=\frac{-U_{\text {surge }}}{1-h}-\max \left|\frac{\eta}{T_{1}(1-h)}\right| \operatorname{sat}\left(\frac{S_{1}}{\phi}\right) .
$$

\subsection{SMC design for sway motion}

The procedure for designing sway input is similar with surge input. The switching function of sway motion is as follows:

$$
S_{2}(v, t)=v-v_{d}
$$

By performing the same steps as in the surge motion, the control system design for sway motion is as follows:

$$
\delta_{1}=\frac{-\left(T_{2} V_{\text {sway }}+T_{3} N_{\text {yaw }}\right)}{T_{2} Y_{\delta}+T_{3} N_{\delta}}-\max \left|\frac{\eta}{T_{2} Y_{\delta}+T_{3} N_{\delta}}\right| \operatorname{sat}\left(\frac{S_{2}}{\phi}\right),
$$

where $\eta$ and $\phi$ are tuning parameters.

\subsection{SMC design for yaw motion}

The procedure for designing yaw input has some similarities to that for surge inputs. The switching function of yaw motion is given by:

$$
S_{3}(r, t)=r-r_{d}
$$

By applying the same steps as for the surge motion, the design of the control system for yaw motion is as follows:

$$
\delta_{2}=\frac{-\left(T_{4} V_{\text {sway }}+T_{5} N_{\text {yaw }}\right)}{T_{4} Y_{\delta}+T_{5} N_{\delta}}-\max \left|\frac{\eta}{T_{4} Y_{\delta}+T_{5} N_{\delta}}\right| \operatorname{sat}\left(\frac{S_{3}}{\phi}\right),
$$

where $\eta$ and $\phi$ are tuning parameters.

\section{RESULTS AND SIMULATION}

After designing the motion control system using the SMC method, then we simulate the results on Matlab's Simulink. This control system is arranged in the form of block diagrams on the motion system of Autonomous Surface Vehicle (ASV) in the form of a closed loop with $\eta=1$ and $\phi=1$. The block diagram of the nonlinear 3-DOF Autonomous Surface Vehicle (ASV) model using the SMC method is presented in Figure 3.

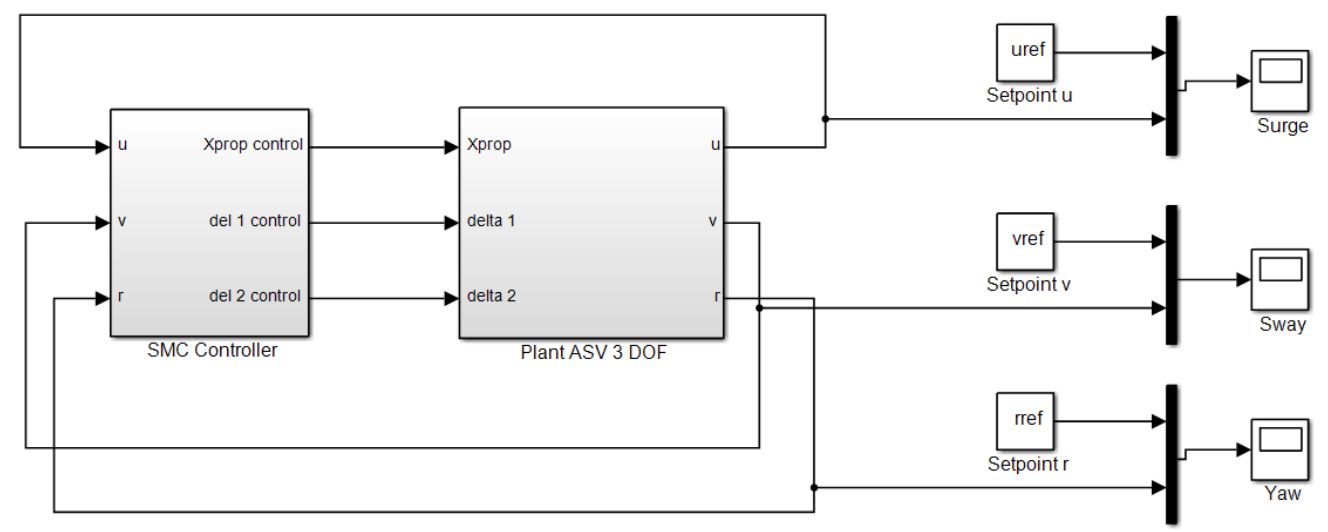

Figure 3. ASV block diagram of the SMC method

After the SMC control system is simulated, the response of surge, sway and yaw motions are displayed in Figure 4(a), Figure 4(b) and Figure 5, respectively. In the simulation, we compare the performance of SMC in the absence of environmental factors and in the presence of environmental factors. 


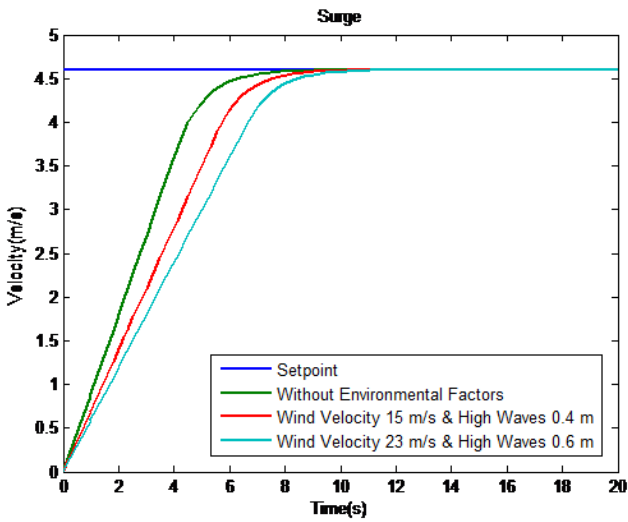

(a)



(b)

Figure 4. Response of surge and sway motions for the disturbance-free case and in the presence of disturbance, (a) surge motion, (b) sway motion

From Figures 4 and 5, it can be seen that the higher wind speed and wave height, the steady-state error is higher and settling time is longer. But the level of the wind speed and the height of the wave has no effect on the overshoot. At a wind speed of $23 \mathrm{~km} / \mathrm{h}$ and a wave height of $0.6 \mathrm{~m}$, the graph shows that it goes away from the setpoint. It appears that the motion is stable and the steady-state error is very small with a setpoint of $4.6 \mathrm{~m} / \mathrm{s}$ for surge, $1 \mathrm{~m} / \mathrm{s}$ for sway and $1 \mathrm{rad} / \mathrm{s}$ for yaw. Figure 4 shows a surge motion response reaching the first time (settling time) at 11 seconds, a steady-state error of $0.17 \%$ and having a $0 \%$ overshoot by presenting an error between a setpoint and a stable position. Figure 4 is the result of a response by the SMC method for sway motion, where the sway motion response reaches settling time at 9.4 seconds, steady-state error of $0.2 \%$ and has a $0 \%$ overshoot. Figure 5 is the result of a response by the SMC method for yaw motion, where the yaw motion response reaches settling time in 8.1 seconds, steady state error $0.2 \%$ and has a $0 \%$ overshoot. The simulation results of the three conditions can be seen in Table 2.

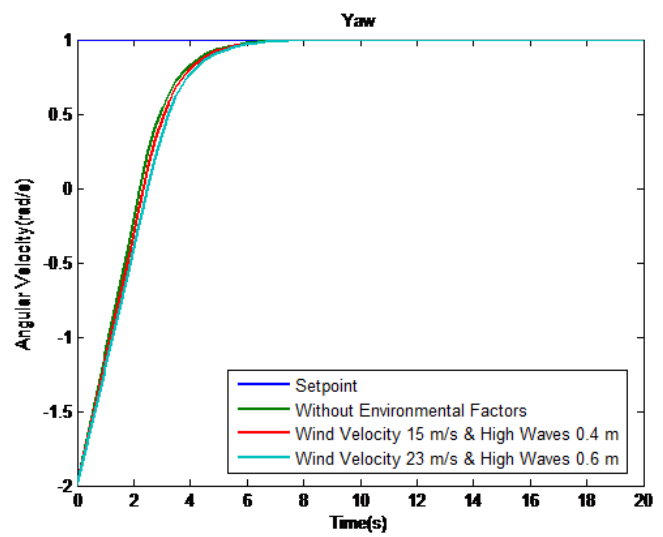

Figure 5. Response of yaw motion for the disturbance-free case and in the presence of disturbance

Table 2. Error and Settling Time for 3-DOF nonlinear model by using SMC

\begin{tabular}{llccccc} 
& \multicolumn{2}{c}{$\begin{array}{c}\text { Without Environmental } \\
\text { Factors }\end{array}$} & \multicolumn{2}{c}{$\begin{array}{c}\text { Wind Velocity } 15 \mathrm{~m} / \mathrm{s} \& \\
\text { High Waves } 0.4 \mathrm{~m}\end{array}$} & \multicolumn{2}{c}{$\begin{array}{c}\text { Wind Velocity } 23 \mathrm{~m} / \mathrm{s} \mathrm{\&} \\
\text { High Waves 0.6 m }\end{array}$} \\
& Error & Settling Time & Error & Settling Time & Error & Settling Time \\
\hline Surge & $0.12 \%$ & $8.5 \mathrm{~s}$ & $0.15 \%$ & $10.1 \mathrm{~s}$ & $0.17 \%$ & $11 \mathrm{~s}$ \\
Sway & $0.14 \%$ & $6.4 \mathrm{~s}$ & $0.17 \%$ & $8 \mathrm{~s}$ & $0.2 \%$ & $9.4 \mathrm{~s}$ \\
Yaw & $0.15 \%$ & $6.5 \mathrm{~s}$ & $0.18 \%$ & $7.2 \mathrm{~s}$ & $0.2 \%$ & $8.1 \mathrm{~s}$ \\
\hline
\end{tabular}




\section{CONCLUSIONS}

Based on the results and analysis related to the design of the ASV motion control system with the Sliding Mode Control (SMC) method for surge, sway and yaw motions, the study of 3-DOF nonlinear models came to the conclusion that if the environmental factor value is higher, then the error produced is also higher. The average error difference between the simulation without environmental factors and that using environmental factors is $0.05 \%$ for surge, sway and yaw motions.

\section{ACKNOWLEDGEMENT}

This work was supported by the Ministry of Research and Higher Education (Kemenristekdikti), Republic of Indonesia contract numbers 945/PKS/ITS/2019, 946/PKS/ITS/2019, 061/SP2H/LT/MONO/L7/2019, and appreciation to the Center of Excellence for Mechatronics and Industrial Automation (PUI-PT MIA-RC ITS) Kemenristekdikti, Republic of Indonesia and thanks to Nurdia Dwi Cahyani for helping the simulation of SMC control system.

\section{REFERENCES}

[1] T. Herlambang, H. Nurhadi, and Subchan, "Preliminary numerical study on designing navigation and stability control systems for its auv," in Applied Mechanics and Materials, vol. 493, pp. 420-425, 2014.

[2] T. Herlambang, E. Djatmiko, and H. Nurhadi, "Ensemble kalman filter with a square root scheme (enkf-sr) for trajectory estimation of auv segorogeni its," International Review of Mechanical Engineering, vol. 9, no. 6, pp. 553-560, 2015.

[3] J. Manley, "Unmanned surface vehicles, 15 years of development," in OCEANS 2008, pp. 1-4, 2008.

[4] V. Bertram, "Unmanned surface vehicles-a survey," Skibsteknisk Selskab, Copenhagen, Denmark, vol. 1, pp. 1-14, 2008.

[5] M. Dunbabin, A. Grinham, and J. Udy, "An autonomous surface vehicle for water quality monitoring," in Australasian conference on robotics and automation (ACRA), pp. 2-4, 2009.

[6] H. Ferreira, C. Almeida, A. Martins, J. Almeida, N. Dias, A. Dias, and E. Silva, "Autonomous bathymetry for risk assessment with roaz robotic surface vehicle," in Oceans 2009-Europe, pp. 1-6, 2009.

[7] H. Ferreira, R. Martins, E. Marques, J. Pinto, A. Martins, J. Almeida, J. Sousa, and E. Silva, "Swordfish: an autonomous surface vehicle for network centric operations," in Oceans 2007-Europe, pp. 1-6, 2007.

[8] S. Fernandez, K. Vijayakumar, R. Palanisamy, K. Selvakumar, D. Karthikeyan, D. Selvabharathi, S. Vidyasagar, and V. Kalyanasundhram, "Unmanned and autonomous ground vehicle," International Journal of Electrical \& Computer Engineering, vol. 9, no. 5, pp. 4466-4472, 2019.

[9] C.-Z. Pan, X.-Z. Lai, S. Yang, and M. Wu, "An efficient neural network approach to tracking control of an autonomous surface vehicle with unknown dynamics," Expert Systems with Applications, vol. 40, no. 5, pp. 1629-1635, 2013.

[10] Z. Peng, D. Wang, Z. Chen, X. Hu, and W. Lan, "Adaptive dynamic surface control for formations of autonomous surface vehicles with uncertain dynamics," IEEE Transactions on Control Systems Technology, vol. 21, no. 2, pp. 513-520, 2012.

[11] M. Bibuli, M. Caccia, and L. Lapierre, "Path-following algorithms and experiments for an autonomous surface vehicle," IFAC Proceedings Volumes, vol. 40, no. 17, pp. 81-86, 2007.

[12] H. Heidarsson and G. Sukhatme, "Obstacle detection and avoidance for an autonomous surface vehicle using a profiling sonar," in International Conference on Robotics and Automation, pp. 731-736, 2011.

[13] N. Aswini and S. Uma, "Obstacle avoidance and distance measurement for unmanned aerial vehicles using monocular vision," International Journal of Electrical \& Computer Engineering (2088-8708), vol. 9, no. 5, pp. 3504-3511, 2019.

[14] M. Wolf, C. Assad, Y. Kuwata, A. Howard, H. Aghazarian, D. Zhu, T. Lu, A. Trebi-Ollennu, and T. Huntsberger, "360-degree visual detection and target tracking on an autonomous surface vehicle," Journal of Field Robotics, vol. 27, no. 6, pp. 819-833, 2010.

[15] T. Herlambang and S. Subchan, "Design of surge and roll motion control system of itsunusa auv using pid controller," International Journal of ASRO-STTAL, vol. 9, no. 1, pp. 139-142, 2018.

[16] T. Herlambang, S. Subchan, and H. Nurhadi, "Design of motion control using proportional integral derivative for unusaits auv," International Review of Mechanical Engineering, vol. 12, no. 11, pp. 553-560, 2018. 
[17] K. Oktafianto, T. Herlambang, Mardlijah, and H. Nurhadi, "Design of autonomous underwater vehicle motion control using sliding mode control method," in International Conference on Advanced Mechatronics, Intelligent Manufacture, and Industrial Automation, pp. 162-166, 2015.

[18] T. Herlambang, "Desain sistem kendali gerak surge, sway dan yaw pada autonomous underwater vehicle dengan metode sliding mode control (smc)," Limits: Journal of Mathematics and Its Applications, vol. 14, no. 1 , pp. 53-60, 2017.

[19] H. Nurhadi, T. Herlambang, and Subchan, "Design of sliding mode control for surge, heave and pitch motion control of unusaits auv," in AIP Conference Proceedings, vol. 2187, no. 1, pp. 060005, 2019.

[20] T. Herlambang and H. Nurhadi, "Design of a sliding pid controller for the surge and roll motion control of unusaits auv," International Journal of Computing Science and Applied Mathematics, vol. 3, no. 2, pp. 61-64, 2017.

[21] T. Herlambang, S. Subchan, H. Nurhadi, and D. Adzkiya, "Motion control design of unusaits auv using sliding pid," Nonlinear Dynamics and Systems Theory, vol. 20, no. 1, pp. 51-60, 2020.

[22] T. Herlambang, D. Rahmalia, and T. Yulianto, "Particle swarm optimization (pso) and ant colony optimization (aco) for optimizing pid parameters on autonomous underwater vehicle (auv) control system," in Journal of Physics: Conference Series, vol. 1211, no. 1, pp. 012039, 2019.

[23] T. Herlambang, E. Djatmiko, and H. Nurhadi, "Navigation and guidance control system of auv with trajectory estimation of linear modelling," in International Conference on Advanced Mechatronics, Intelligent Manufacture, and Industrial Automation, pp. 184-187, 2015.

[24] H. Nurhadi, T. Herlambang, and D. Adzkiya, "Position estimation of touristant asv using ensemble kalman filter," in AIP Conference Proceedings, vol. 2187, no. 1, pp. 060006, 2019.

[25] Z. Ermayanti, E. Apriliani, H. Nurhadi, and T. Herlambang, "Estimate and control position autonomous underwater vehicle based on determined trajectory using fuzzy kalman filter method," in International Conference on Advanced Mechatronics, Intelligent Manufacture, and Industrial Automation, pp. 156-161, 2015. 